\title{
A COMPARATIVE RADIOLOGICAL STUDY OF REITER'S DISEASE, RHEUMATOID ARTHRITIS AND ANKYLOSING SPONDYLITIS
}

\author{
R. M. Mason, R. S. Murray, J. K. Oates and A. C. Young, London, England
}

From the London Hospital

In a previous communication (Mason, Murray, Oates and Young 1958) we have described three groups of patients studied at the London Hospital in whom a diagnosis of Reiter's disease, rheumatoid arthritis and ankylosing spondylitis had been made. Reasons were given for regarding these as distinct entities and attention was drawn to the differences found in age distribution, in the incidence of inflammatory genital disease, in serology and in involvement of the sacro-iliac joints. The clinical features of the patients with Reiter's disease have been described by King (1957) and by Oates (1957); the radiological features were reported by Murray, Oates and Young (1958), who pointed out their similarity to those found in rheumatoid arthritis and ankylosing spondylitis. Previous accounts of the radiological appearances in Reiter's disease have usually been limited to isolated findings. Most workers have commented on the periostitis (Hollander, Fogarty, Abrams and Kydd 1945; Harkness 1950; Guck and Wolf 1952; Sharp 1957), especially that affecting the calcaneum (Ford 1953). Others have emphasised osteoporosis (Twiss and Douglas 1946, Corner 1950); however, Paronen (1948) found no radiological changes in 334 patients with post-dysenteric Reiter's disease and in 1955 Buchan stated that the radiological changes are "non-specific." Marche (1950). Ford (1953), Sharp (1957), Thompson (1957) and Mason et al. (1958) have all been impressed with the high incidence of " sacro-iliitis."

TABLE I

Age Distribution of the Patients Studied

\begin{tabular}{|c|c|c|c|c|c|c|c|c|c|c|c|c|c|c|}
\hline \multirow[t]{2}{*}{ Age in years } & \multicolumn{2}{|c|}{$15-24$} & \multicolumn{2}{|c|}{$25-34$} & \multicolumn{2}{|c|}{$35-44$} & \multicolumn{2}{|c|}{$45-54$} & \multicolumn{2}{|c|}{$55-64$} & \multicolumn{2}{|c|}{$65-74$} & 75 onw & ards \\
\hline & Number & $\begin{array}{l}\text { Per } \\
\text { cent }\end{array}$ & Number & $\begin{array}{l}\text { Per } \\
\text { cent }\end{array}$ & Number & $\begin{array}{l}\text { Per } \\
\text { cent }\end{array}$ & Number & $\begin{array}{l}\text { Per } \\
\text { cent }\end{array}$ & Number & $\begin{array}{l}\text { Per } \\
\text { cent }\end{array}$ & Number & $\begin{array}{l}\text { Per } \\
\text { cent }\end{array}$ & Number & $\begin{array}{l}\text { Per } \\
\text { cent }\end{array}$ \\
\hline $\begin{array}{l}\text { Reiter`s } \\
\text { disease }\end{array}$ & 3 & 12 & 4 & 16 & 6 & 24 & 6 & 24 & 2 & 8 & 3 & 12 & 1 & 4 \\
\hline $\begin{array}{l}\text { Rheumatoid } \\
\text { arthritis }\end{array}$ & & & 5 & 6 & 14 & 17 & 28 & 35 & 23 & 28 & 11 & 14 & & \\
\hline $\begin{array}{l}\text { Ankylosing } \\
\text { spondylitis }\end{array}$ & 8 & 21 & 6 & 16 & 16 & 42 & 6 & 16 & 2 & 5 & & & & \\
\hline
\end{tabular}

This report records an examination of the radiological findings in the three groups of patients already mentioned. The clinical material consisted of fifty-nine patients with Reiter's disease, eighty-six with rheumatoid arthritis and fifty-four (all men) with ankylosing spondylitis. but the comparison was limited to those patients in whom certain specified joints were radiographed, independent of joint involvement: all these patients had routine radiographs of hands, feet, ankles (including the calcaneum) and pelvis. The radiographs were examined by two of the authors together (with a few isolated exceptions), from whom the clinical findings had been concealed. Under these circumstances the radiographs of 144 patients were available for comparison, of whom twenty-five had Reiter's disease, eighty-one had rheumatoid arthritis and thirty-eight had ankylosing spondylitis.

Table I shows the age distribution of the patients whose hands, feet, ankles and pelves

VOL. 41 B, NO. 1, FEBRUARY 1959 
TABLE II

Distribution of the Patients Studied According to the Duration of the Disease

\begin{tabular}{|c|c|c|c|c|c|c|c|c|}
\hline \multirow[t]{2}{*}{ Duration in years } & \multicolumn{2}{|c|}{$0-1$} & \multicolumn{2}{|c|}{$1-4$} & \multicolumn{2}{|c|}{$5-9$} & \multicolumn{2}{|c|}{10 onwards } \\
\hline & Number & Per cent & Number & Per cent & Number & Per cent & Number & Per cent \\
\hline Reiter's disease . & 4 & 16 & 8 & 32 & 2 & 8 & 11 & 44 \\
\hline Rheumatoid arthritis & 6 & 7 & 36 & 44 & 21 & 26 & 18 & 22 \\
\hline Ankylosing spondylitis & & & 11 & 29 & 13 & 33 & 14 & 37 \\
\hline
\end{tabular}

TABLE III

InCidence and Distribution of Radiological Changes

\begin{tabular}{|c|c|c|c|c|c|c|c|c|}
\hline & & & \multicolumn{2}{|c|}{$\begin{array}{l}\text { Reiter's } \\
\text { disease }\end{array}$} & \multicolumn{2}{|c|}{$\begin{array}{l}\text { Rheumatoid } \\
\text { arthritis }\end{array}$} & \multicolumn{2}{|c|}{$\begin{array}{l}\text { Ankylosing } \\
\text { spondylitis }\end{array}$} \\
\hline & & & Number & Per cent & Number & Per cent & Number & Per cent \\
\hline \multirow{2}{*}{ Sacro-iliitis } & Cilateral & . & 8 & 32 & 8 & 10 & 38 & 100 \\
\hline & Unilateral & . & 0 & 0 & 10 & 12 & 0 & 0 \\
\hline \multirow{8}{*}{$\begin{array}{l}\text { Periosteal } \\
\text { new bone } \\
\text { formation }\end{array}$} & Malleoli . & . & 12 & 48 & 41 & 50 & 12 & 31 \\
\hline & Tarsals . & . & 4 & 16 & 21 & 26 & 1 & 3 \\
\hline & Metatarsals & . & 2 & 8 & 1 & 1 & 3 & 8 \\
\hline & Metacarpals & . & 0 & 0 & 0 & 0 & 0 & 0 \\
\hline & Phalanges (h & land) & 2 & 8 & 8 & 10 & 0 & 0 \\
\hline & Phalanges ( $f$ & oot) & 0 & 0 & 3 & 4 & 1 & 3 \\
\hline & Wrist & . & 4 & 16 & 4 & 5 & 2 & 5 \\
\hline & Pelvis & . & 1 & 4 & 0 & 0 & 4 & 11 \\
\hline \multirow{6}{*}{$\begin{array}{l}\text { Calcaneal } \\
\text { changes }\end{array}$} & \multirow{2}{*}{ Periostitis \{} & Posterior & 6 & 24 & 17 & 21 & 4 & 11 \\
\hline & & Plantar. & 5 & 20 & 3 & 4 & 2 & 5 \\
\hline & \multirow{2}{*}{ Spur } & Posterior & 8 & 32 & 12 & 15 & 2 & 5 \\
\hline & & Plantar. & 10 & 40 & 32 & 39 & 9 & 24 \\
\hline & \multirow{2}{*}{ Erosion } & Posterior & 7 & 28 & 14 & 17 & 7 & 18 \\
\hline & & Plantar & 1 & 4 & 3 & 4 & 1 & 3 \\
\hline \multirow{2}{*}{\multicolumn{2}{|c|}{ Peripheral arthropathy \{}} & Hands. & 7 & 28 & 66 & 81 & 4 & 11 \\
\hline & & Feet & 12 & 48 & 62 & 76 & 9 & 24 \\
\hline
\end{tabular}

were radiographed, with a similar pattern throughout and no special bias towards any one age group so far as this radiological study is concerned. Table II gives the distribution of patients studied according to the duration of the disease.

\section{INCIDENCE AND DISTRIBUTION OF RADIOLOGICAL CHANGES}

The following radiological features were recorded using the criteria described by Murray et al. (1958).

Sacro-iliitis-This was noted as bilateral or unilateral, equivocal or unequivocal. Sacro-iliitis in the present report refers only to those recorded as unequivocal. 
Periosteal new bone-This was looked for on the bones of the pelvis, wrists, hands, fingers, ankles, feet and toes.

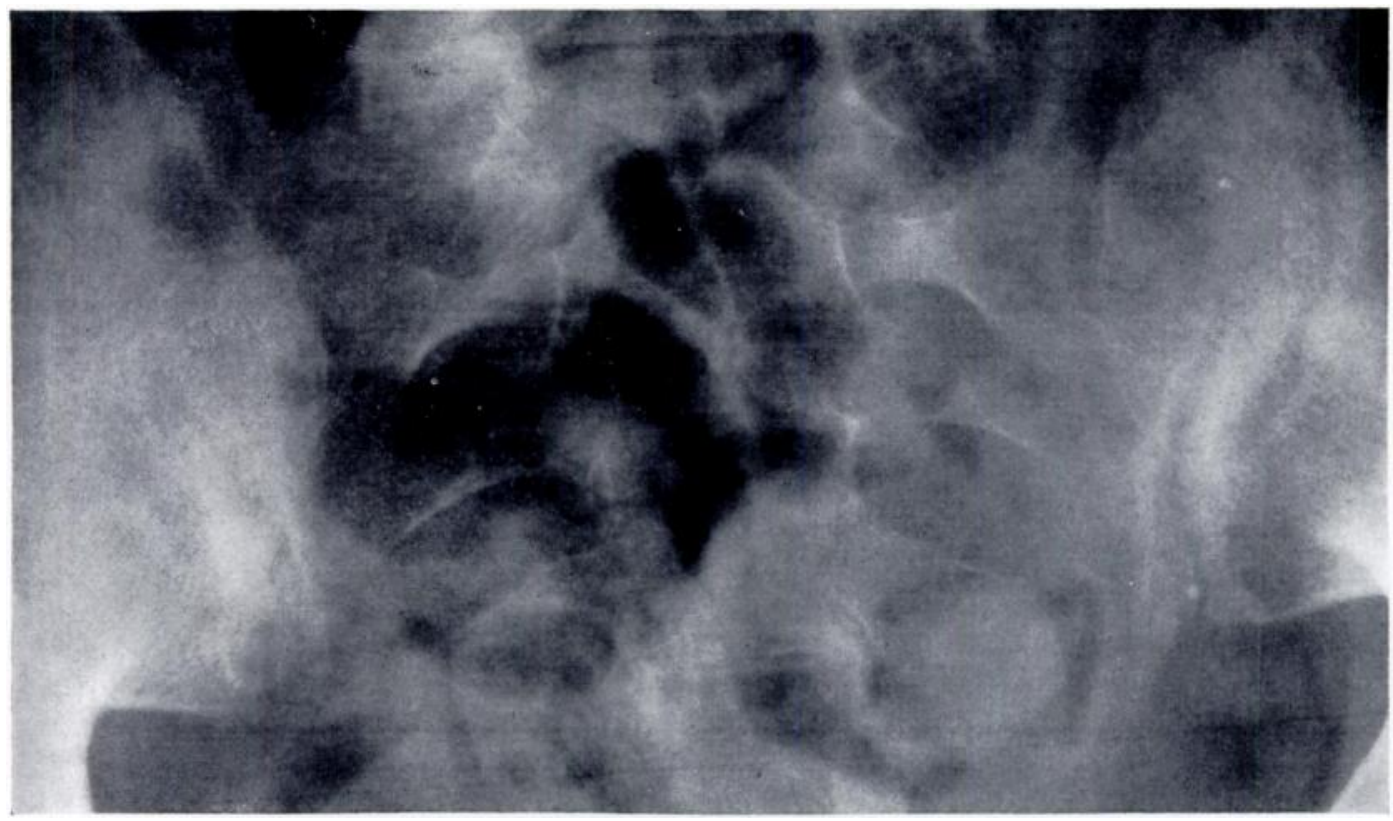

Fig. 1

The sacro-iliac joints in Reiter's disease, showing mild changes with loss of cortex, widening. minimal erosions and sclerosis.

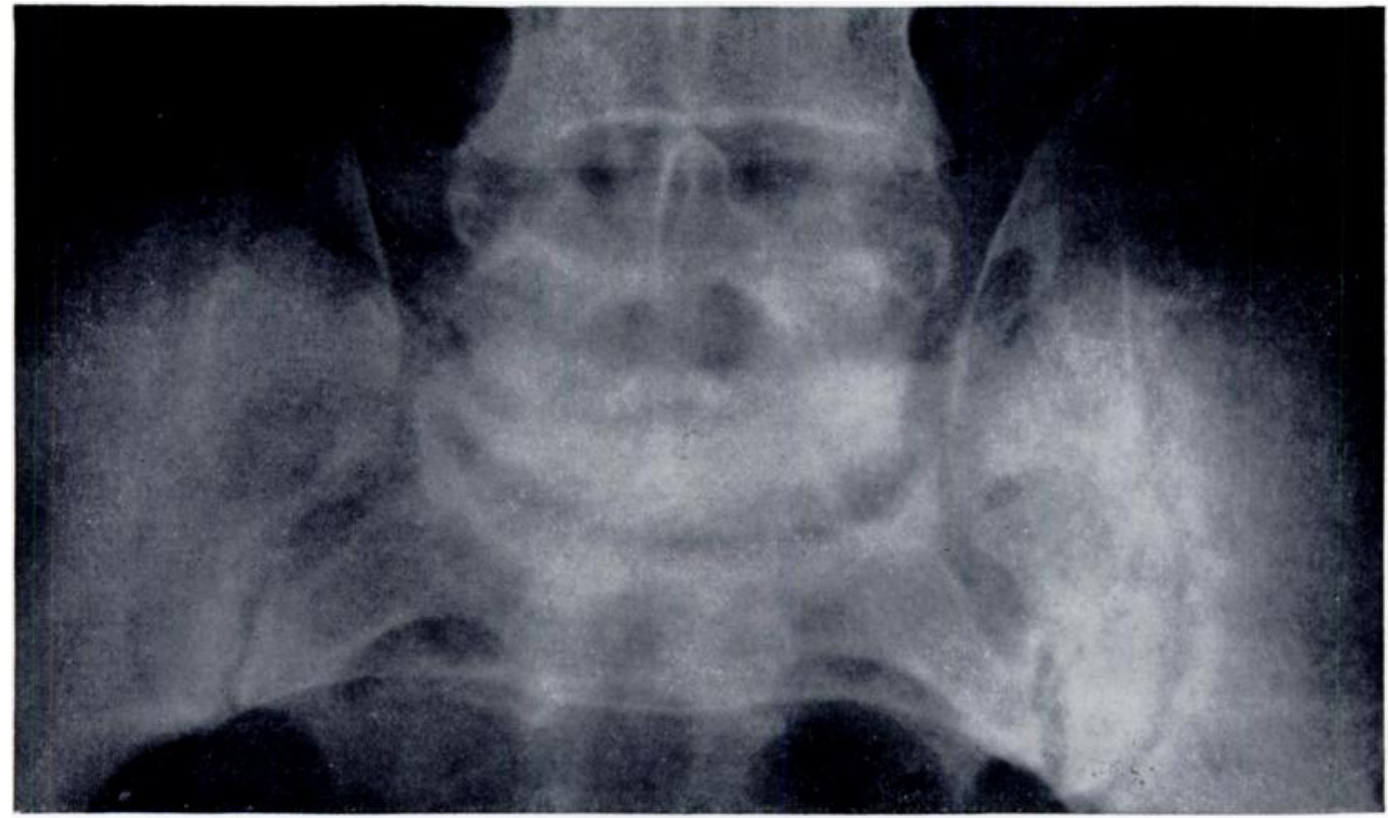

Fig. 2

The sacro-iliac joints in rheumatoid arthritis, showing loss of cortex, slight widening, mild erosions and moderate sclerosis.

Calcaneal spur formation-This was distinguished as far as possible from periosteal new bone. Erosions were also recorded, posterior and plantar sites being noted separately.

VOL. $41 \mathrm{~B}$, NO. 1, FEBRUARY 1959 
Peripheral arthritis-Destructive changes in hands, wrists and feet were recorded together with their distribution, both as between hands and feet and within the hand itself.

Osteoporosis was not analysed. Kellgren and Lawrence (1957) have recently commented on the observer error which may arise in assessing lesser degrees of osteoporosis.

The incidence and distribution of these lesions is shown in Table III.

\section{SACRO-ILIITIS}

Unequivocal bilateral sacro-iliitis was seen in eight out of the twenty-five patients with Reiter's disease ( 32 per cent) compared with eight out of eighty-one with rheumatoid arthritis ( 10 per cent) and in all the thirty-eight patients suffering from ankylosing spondylitis (100 per cent). Unilateral sacro-iliitis was seen in ten, or 12 per cent, of the patients with rheumatoid arthritis. That sacro-iliitis often occurs in rheumatoid arthritis is well recognised (Sharp 1957).

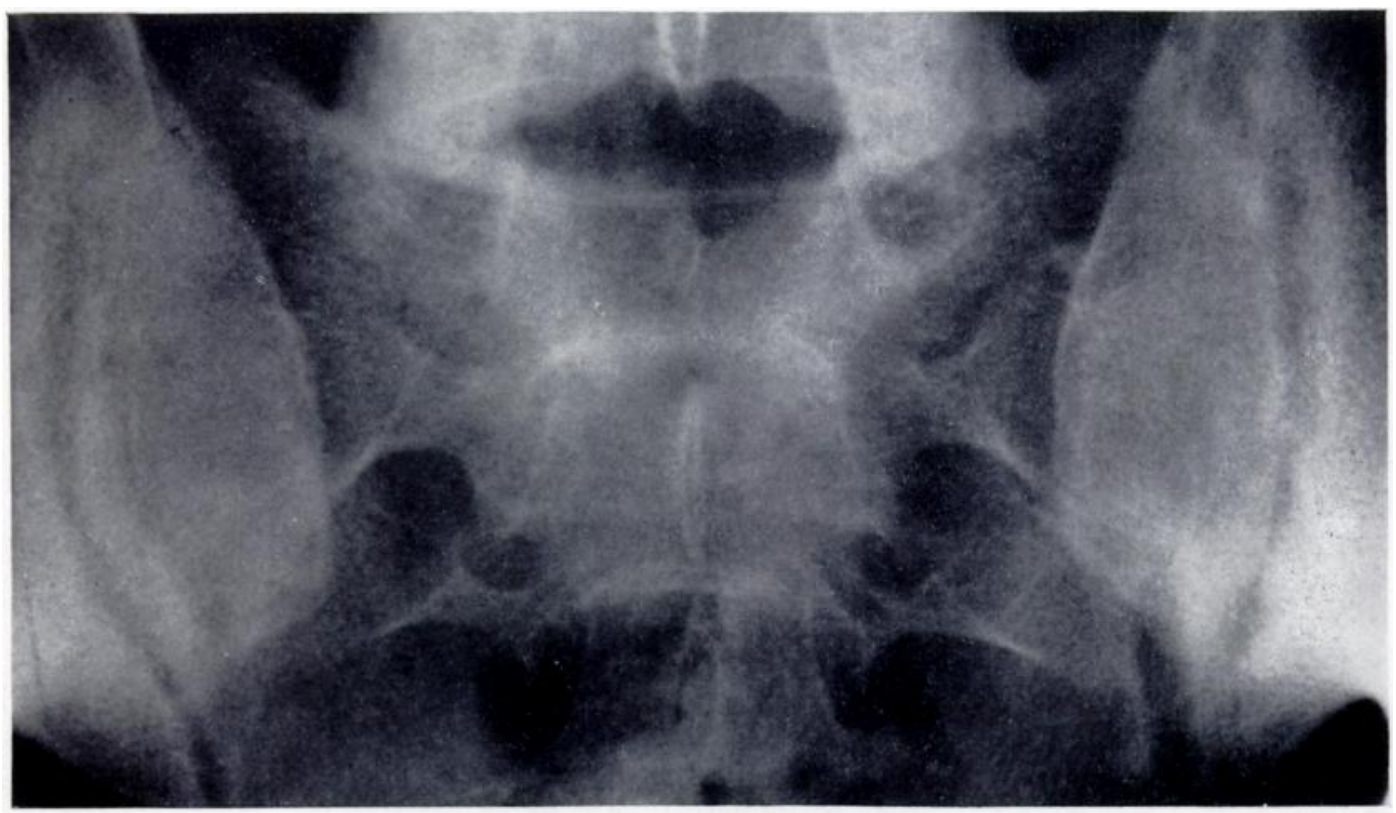

Fig. 3

The sacro-iliac joints in ankylosing spondylitis, showing mild changes with loss of cortex, apparent widening and minimal sclerosis.

Unilateral sacro-iliitis was not seen in any of the patients with Reiter's disease or ankylosing spondylitis in this series, although it has been found in several other patients with Reiter's disease not included here because the radiological survey was incomplete. When the changes in the sacro-iliac joints were mild we were unable to distinguish any qualitative difference between the three diseases (Figs. 1 to 3), but severe erosions, marked sclerosis and particularly ankylosis were found only in Reiter's disease and ankylosing spondylitis (Figs. 4 and 5). Sharp (1957) on the other hand stated that he had observed fusion of the sacro-iliac joints in rheumatoid arthritis. Differences in the time of development of sacro-iliitis were, however, found (Table IV). The incidence of sacro-iliitis increased to 54 per cent in the patients with Reiter's disease with a history of five years or more, but in the patients with rheumatoid arthritis with a similar history the incidence increased to only 15 per cent.

\section{PERIOSTEAL NEW BONE}

We had formed the clinical impression that periosteal new bone was more commonly found in Reiter's disease than in the other disorders, but our findings in this comparatively 
small series do not strongly support this, certainly so far as the incidence rather than the quality of the periostitis is concerned (Table III). Malleolar periosteal new bone was observed in half of the patients with Reiter's disease and rheumatoid arthritis and in one-third of those

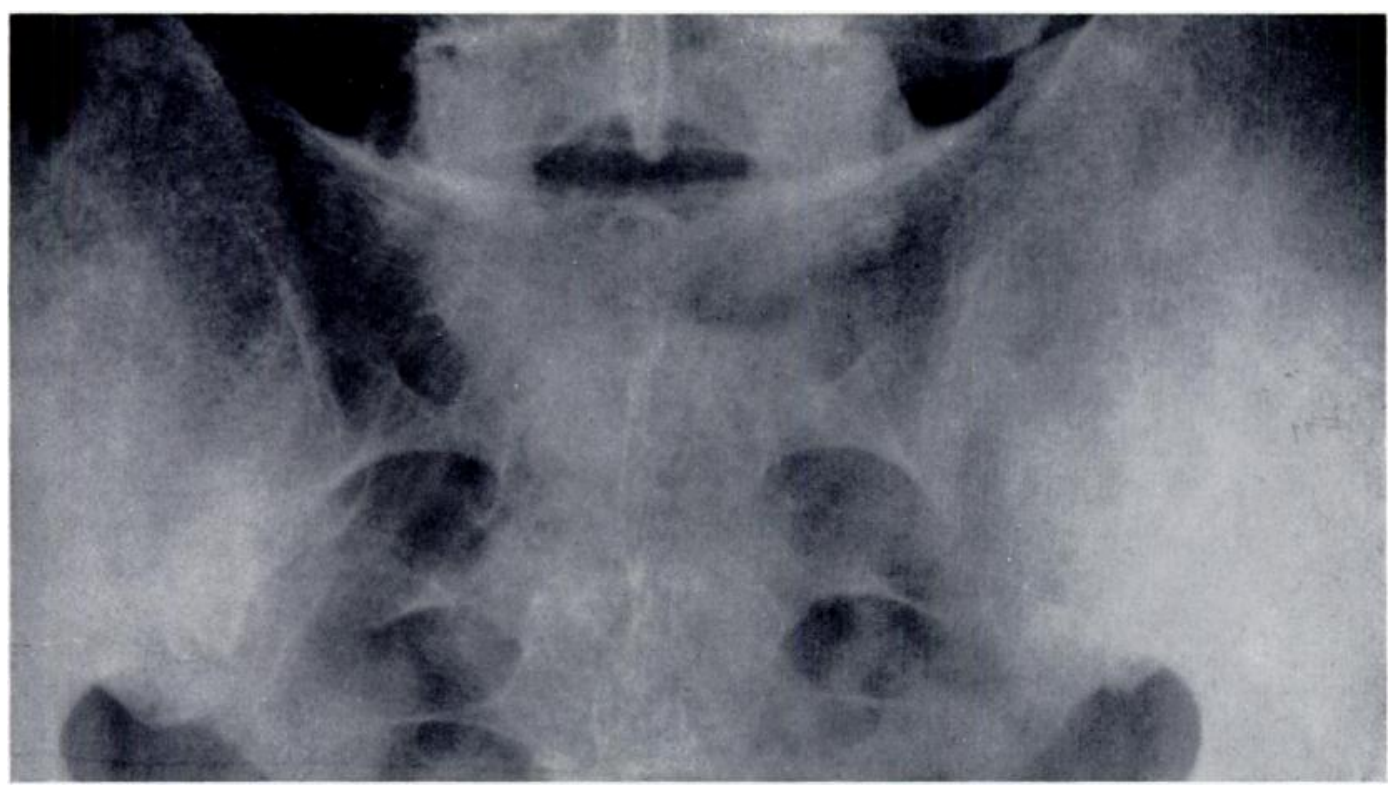

Fig. 4

Reiter's disease in a patient with a fifteen-year history, showing ankylosis of the sacro-iliac joints.

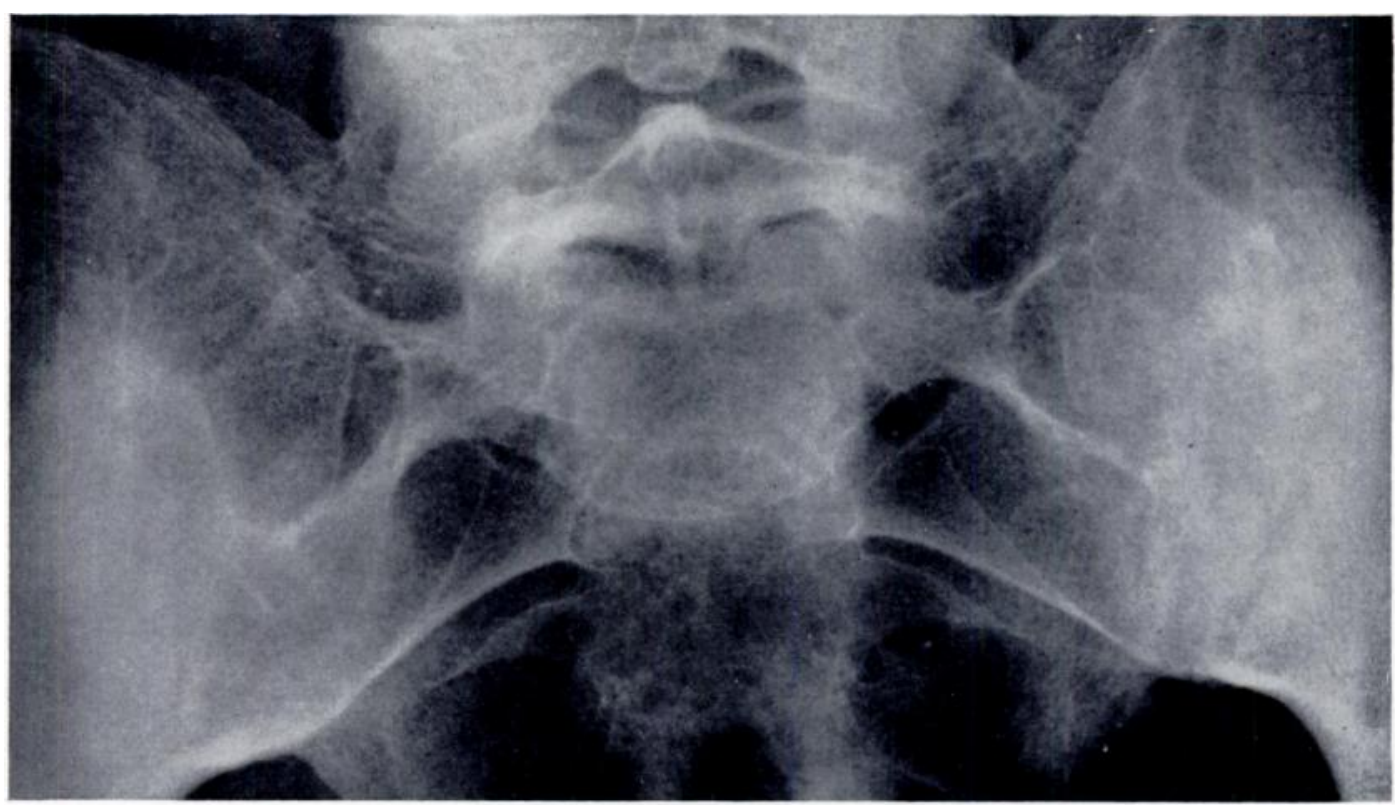

Fig. 5

Advanced ankylosis of sacro-iliac joints in ankylosing spondylitis.

with ankylosing spondylitis (Figs. 6 to 8 ). Tarsal periostitis was seen in only one patient with ankylosing spondylitis and in one-quarter or less of those with rheumatoid arthritis or Reiter's disease. It was uncommon elsewhere although the incidence of 16 per cent in the wrists of

VOL. 41 B, NO. 1, FEBRUARY 1959 
TABLE IV

Incidence of Bilateral Sacro-ilitis in Reiter's Disease Correlated with the Disease Duration and Compared with Similar findings in Rheumatoid Arthritis and Ankylosing Spondylitis

\begin{tabular}{|c|c|c|c|c|}
\hline \multirow[t]{2}{*}{ Duration of disease } & \multicolumn{2}{|c|}{ Less than five years } & \multicolumn{2}{|c|}{ More than five years } \\
\hline & Number & Per cent & Number & Per cent \\
\hline Reiter's disease & 1 out of 12 & 8 & 7 out of 13 & 54 \\
\hline Rheumatoid arthritis . & 2 out of 42 & 5 & 6 out of 39 & 15 \\
\hline Ankylosing spondylitis & 11 out of 11 & 100 & 27 out of 27 & 100 \\
\hline
\end{tabular}

patients with Reiter's disease was three times as common as in rheumatoid arthritis. It was found difficult to interpret accurately the periosteal new bone about the pelvis, particularly as our patients were drawn from the heavy labouring class of east London. Thus the distribution of periosteal new bone outside the calcaneum does not seem to be a differentiating factor, although florid, fluffy periosteal new bone does appear to be a feature of Reiter's disease and of ankylosing spondylitis, where it is seen characteristically in the pelvis and wrist; we have not seen this appearance in rheumatoid arthritis.

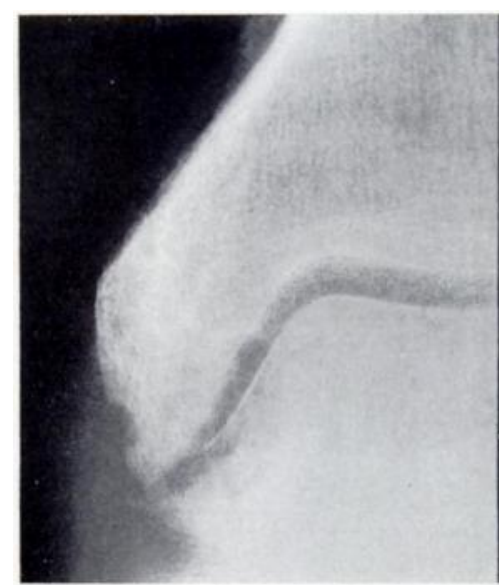

FIG. 6

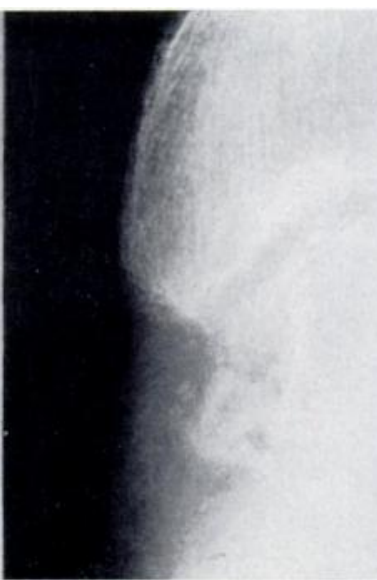

FIG. 7

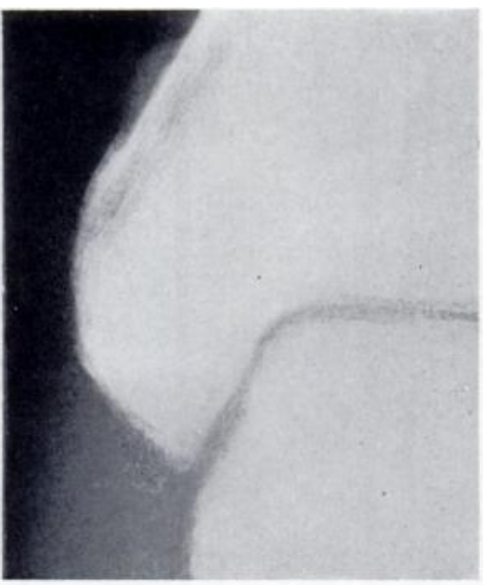

Fig. 8

Figure 6-Malleolar new bone formation in Reiter's disease. Compare with Figure 7 which shows a similar formation in rheumatoid arthritis and in ankylosing spondylitis in Figure 8.

\section{THE CALCANEUM}

Calcaneal spurs were of two types, a simple form (Figs. 9 to 11) in which the margin was clearly defined and which was not associated with changes beyond the base of the spur, and a fluffy form in which the spur was irregular and associated with periosteal new bone elsewhere on the calcaneum, especially on the plantar surface (Figs. 12 to 17). The simple spur appears to be an ossification in the attachment of the fibres of the long plantar ligament, whereas periostitis is a more diffuse process leading to thickening, increased density and the production of a fluffy outline of the plantar surface of the tuberosity and the plantar surface beyond it. In some cases it appears that this periostitis was laid down on a pre-existing simple spur (Fig. 13). Clearly further careful study of the radiological appearance and natural history of spurs and spur formation is required. Simple plantar spurs were observed commonly in all three groups (Table III), in 40 per cent of the patients with Reiter's disease, 39 per cent of those with rheumatoid arthritis and 24 per cent of those with ankylosing spondylitis. 
Posterior spurs were, however, commoner in Reiter's disease with an incidence of 32 per cent compared with 15 per cent in rheumatoid arthritis and 5 per cent in ankylosing spondylitis. Periostitis of the posterior aspect of the calcaneum occurred in 24 per cent of the patients with Reiter's disease, in 21 per cent of those with rheumatoid arthritis and in 11 per cent of those with ankylosing spondylitis, but these differences are not significant. On the plantar surface, however, the incidence was significantly different $(P<0.01)$, periostitis occurring in 20 per cent of the patients with Reiter's disease and in only three patients ( 4 per cent) with rheumatoid arthritis and two (5 per cent) with ankylosing spondylitis. The five patients with rheumatoid arthritis or ankylosing spondylitis were, therefore, carefully reviewed and the accuracy of the diagnosis was critically re-examined.

FIG. 9

A " simple" form of calcaneal spur in Reiter's disease.

FIG. 10

Spur in rheumatoid arthritis.

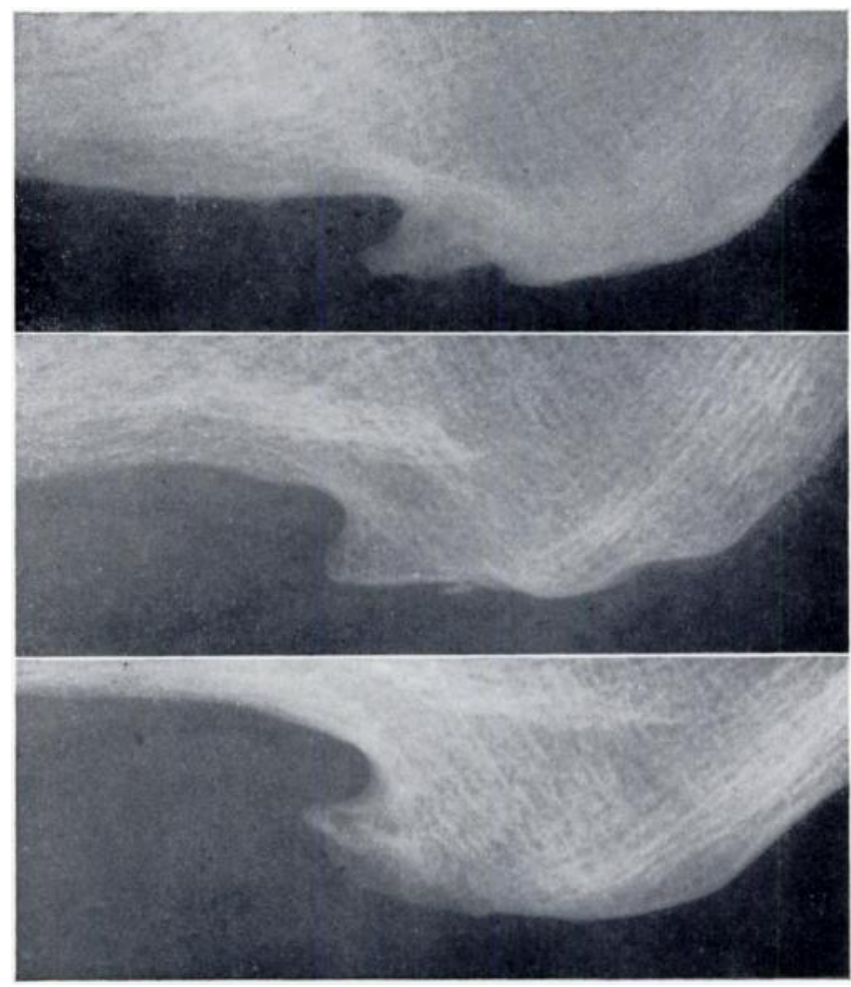

Fig. 11

Spur in ankylosing spondylitis.

CASE REPORTS

Case 151-A patient aged twenty-one was, six years previously, kicked on the back of the left heel. The injury led to severe pain which prevented walking for many months and which was treated with a below-knee plaster. No relief from pain was gained, and after four years a swelling on the back of the heel was treated by an operation, probably to remove a "spur." Involvement of the metatarsophalangeal joints followed with low backache later; there was no urethritis or other genito-urinary symptoms. The radiographs showed bilateral sacro-iliitis, and prostatic fluid contained clumps of leucocytes. Treatment with radiotherapy gave a moderate response.

Comment-This patient was diagnosed as having ankylosing spondylitis but may have had an atypical spondylitis.

Case 158-A patient aged forty-three had been operated upon for claw toes secondary to poliomyelitis affecting the right leg. A left calcaneal spur had been treated by operation; in 1949 he had been treated for conjunctivitis. Clinically a stiff lumbar spine was found and radiographs showed a mild sacro-iliitis with considerable anterior and lateral bridging of the lumbar vertebrae. Genital examination revealed a chronic prostatitis.

Comment-This patient, who had also been diagnosed as having ankylosing spondylitis, perhaps had an atypical spondylitis.

VOL. $41 \mathrm{~B}$, NO. 1, FEBRUARY 1959 
Case 127-A patient aged thirty-three had sero-positive rheumatoid arthritis with nodules, including one over the calcaneal tendon. The severe progressive arthropathy was treated with steroids. The radiographs showed equivocal unilateral sacro-iliitis. There was also a marked chronic non-specific prostatitis with early-morning non-gonococcal urethral discharge.

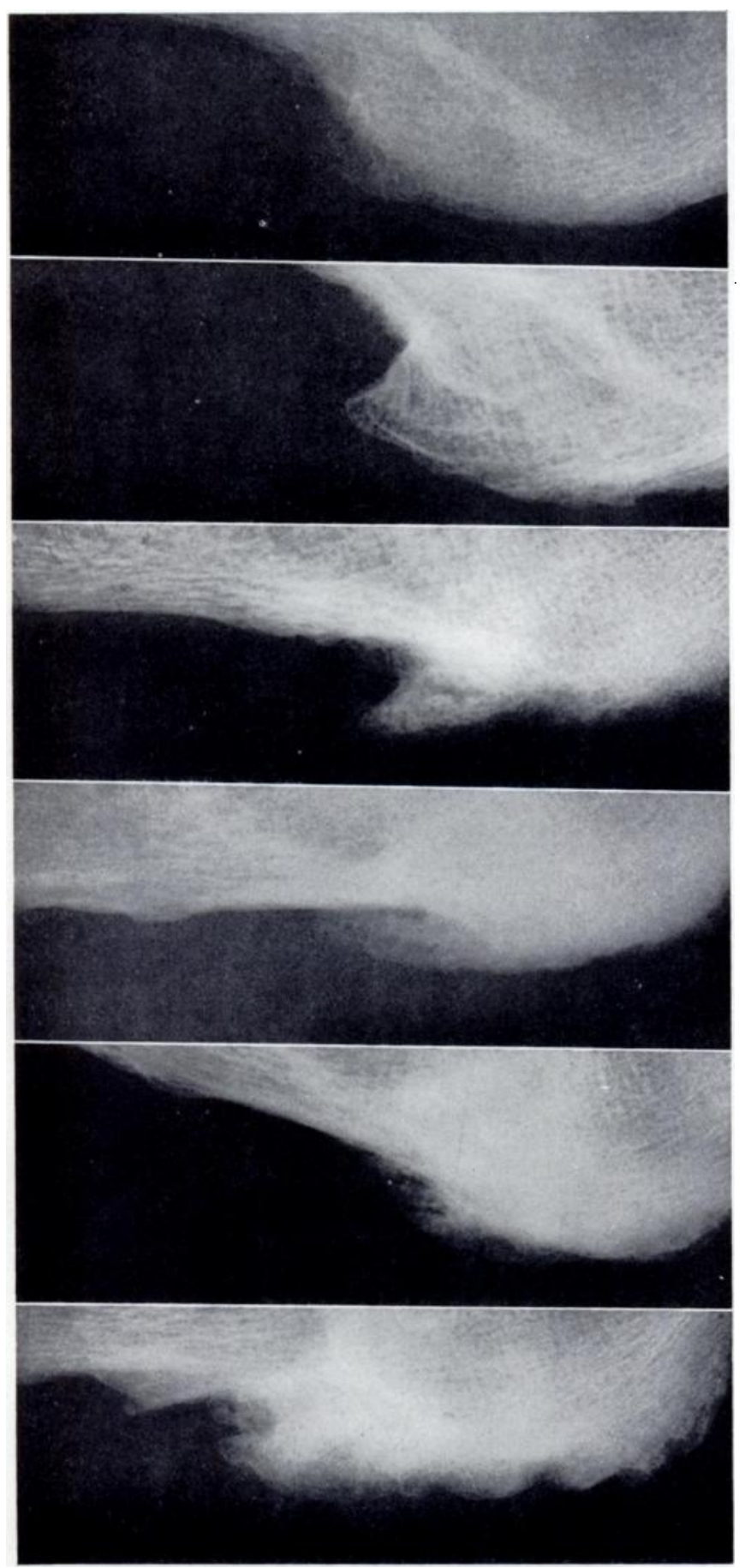

FIG. 12

Calcaneal periosteal new bone in Reiter's disease, shown as an early reaction on the plantar surface.

FIG. 13

New bone in Reiter's disease, apparently superimposed on a

pre-existing simple spur.

FIG. 14

Reiter's disease. An irregular spur is associated with periosteal new bone.

Fig. 15

Reiter's disease. An irregular spur is associated with periosteal new bone.

\section{Fig. 16}

Reiter's disease. Multiple plantar spurs associated with periosteal new bone formation.

Comment-Although this patient had been classified as having rheumatoid arthritis, it is thought that Reiter's disease was present as well.

Case 122-A patient aged fifty-six who had sero-negative rheumatoid arthritis and who refused prostatic 
massage (our only patient to do so) showed bilateral sacro-iliitis and a fluffy periostitis at the wrist in the radiographs.

Comment-Classified as rheumatoid arthritis, the diagnosis could be Reiter's disease.

Case 123-A patient aged fifty-seven with sero-negative rheumatoid arthritis had radiographs showing bilateral sacro-iliitis; he also had a marked chronic prostatitis.

Comment-Again classified as rheumatoid arthritis, the diagnosis could be Reiter's disease.

Thus in only one of these five patients (Case 127) is the diagnosis beyond suspicion. It seems that plantar periostitis of the calcaneum is very strongly suggestive of Reiter's disease and that it is this process which gives rise in some patients to the fluffy dense spurred calcaneum which is so striking a feature of this condition.

Erosions of the calcaneum, especially on its posterior aspect, occurred in all three groups (Figs. 18 to 20). The appearance resembled that described by Bywaters (1954), the incidence in Reiter's disease being 28 per cent, in ankylosing spondylitis 18 per cent and in rheumatoid arthritis 17 per cent.

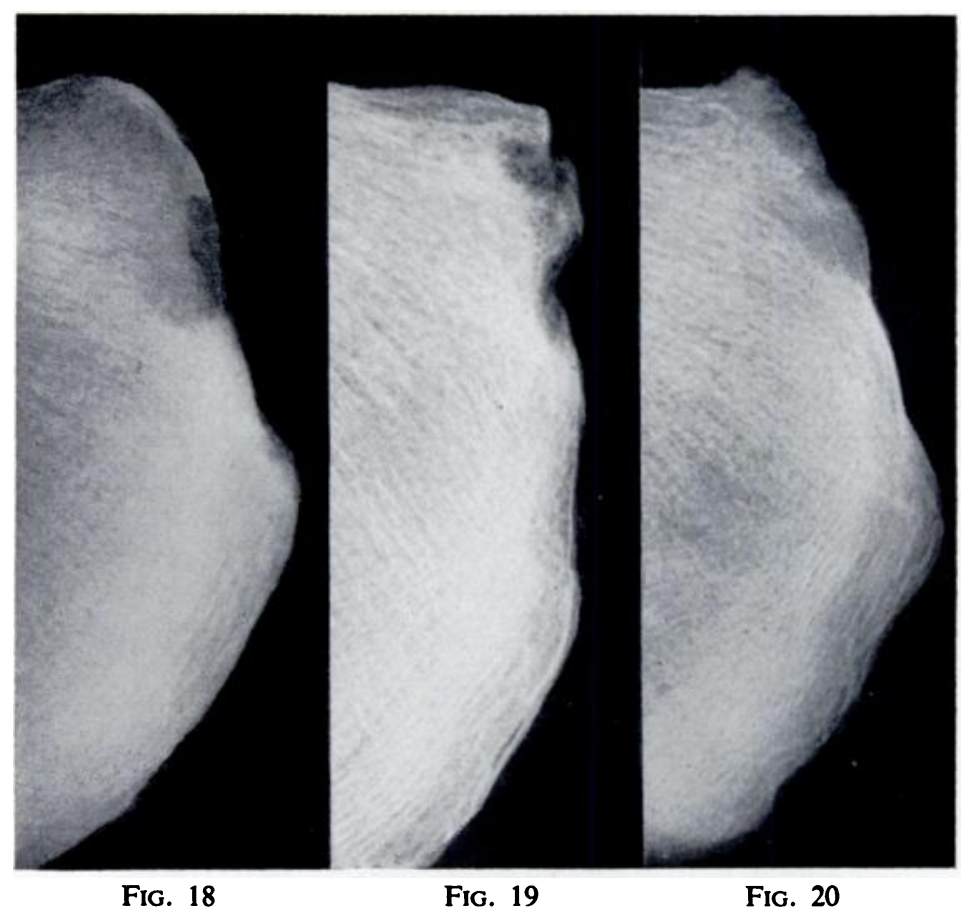

Figure 18-Compare this posterior calcaneal erosion in Reiter's disease with that in rheumatoid arthritis shown in Figure 19 and ankylosing spondylitis in Figure 20.

\section{PERIPHERAL ARTHROPATHY}

Table III shows the preponderance of foot involvement over hand in both Reiter's disease and ankylosing spondylitis compared with rheumatoid arthritis; in the latter disease the hands and feet are affected radiologically in approximately equal proportions. The feet are more commonly and generally much more severely affected than the hands in Reiter's disease, and when the hands are affected the feet may be expected to show severe changes. Severe foot changes may be present, however, with normal or mildly affected hands in Reiter's disease. This is not a feature of rheumatoid arthritis.

Table $\mathrm{V}$ analyses all the hands that were radiographed in the material from which this series was drawn, and therefore includes additional patients to those fully covered radiologically. Only six patients with ankylosing spondylitis showed hand changes and have not been analysed.

VOL. $41 \mathrm{~B}$, NO. 1, FEBRUARY 1959 
TABLE V

Distribution and Incidence of Lesions in the Hand, Showing the Incidence in those Patients in whom the Hand is AbNormal

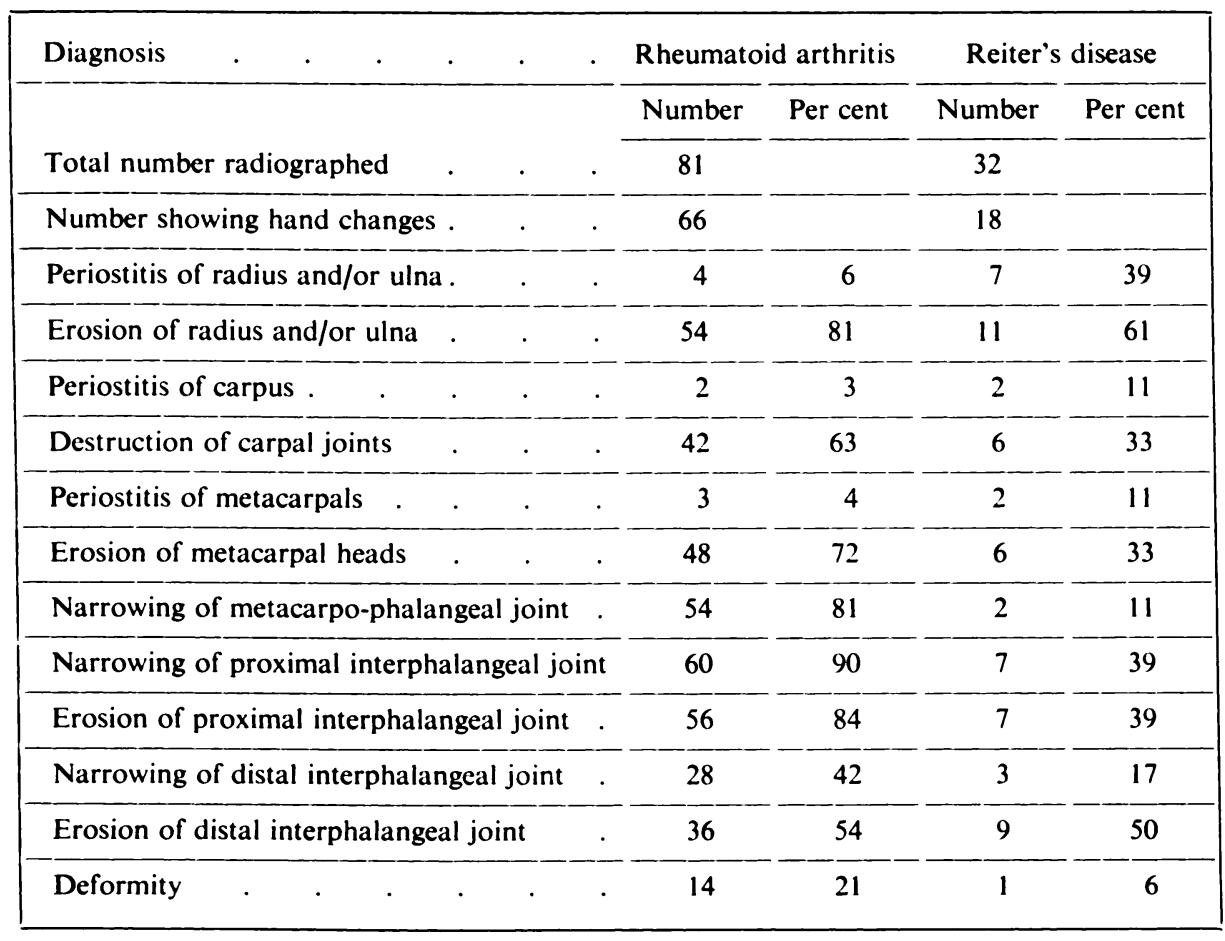

In Reiter's disease changes in the hands are not only less common than in rheumatoid arthritis but they are also milder or more sporadic, and the individual hands show less numerous lesions. The wrists may show occasionally severe changes in Reiter's disease with destruction (Fig. 21), sometimes with fluffy periostitis (Fig. 22), and ankylosis with deformity was observed in one case (Fig. 23). In the past this appearance would probably have been described as

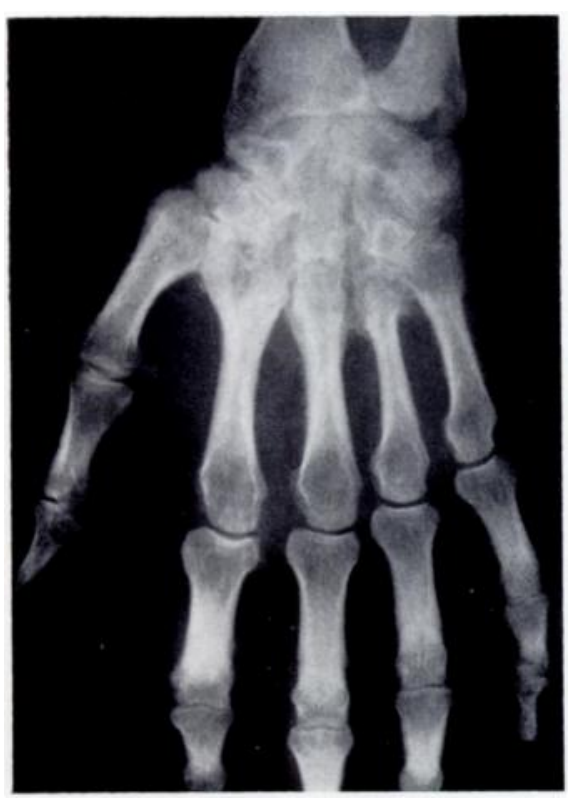

FIG. 21 typical of gonococcal arthritis. Severe wrist changes are more often seen in rheumatoid arthritis and linear periostitis of the ulna and radius may look similar in both (Figs. 24 and 25), but of the patients with rheumatoid arthritis only two showed fluffy periostitis of the wrist: one was sero-negative and had chronic prostatitis; the other was also sero-negative and refused prostatic massage (Case 122 already described). Ulnar deviation of the fingers was not seen in Reiter's disease, nor was generalised osteoporosis in the hand. In comparing the incidence of the involvement of the various joints in the hand destructive changes predominated in the proximal interphalangeal joint in rheumatoid arthritis in 84

FIG. 21

The wrist and hand in a patient with Reiter's disease showing severe wrist and carpal changes with periosteal new bone formation at the bases of the metacarpals. There is relatively mild interphalangeal joint involvement and the metacarpophalangeal joints are spared. 


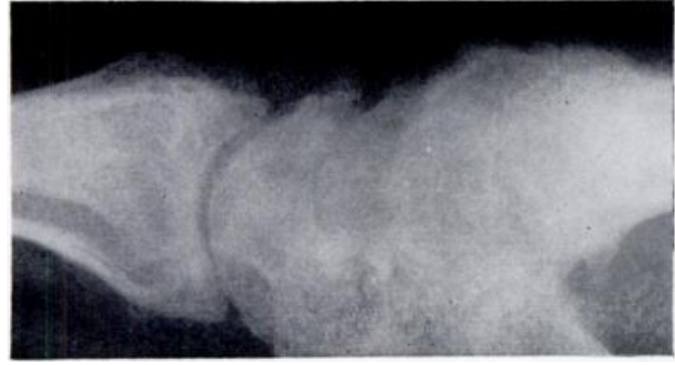

Fig. 22

Figure 22-Fluffy periostitis of the wrist in Reiter's disease. Figure 23-Fluffy periostitis and ankylosis in deformity of the wrist in Reiter's disease.

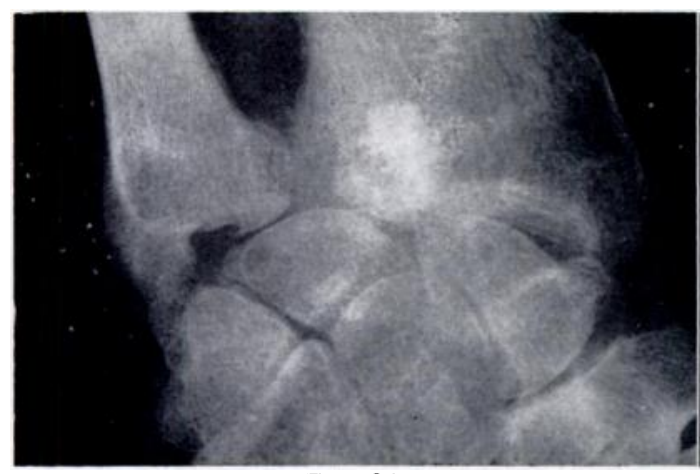

Fig. 24 Figure 24-Linear periosteal new bone at the wrist in Reiter's disease. Compare with Figure 25, showing a
similar condition in rheumatoid arthritis.

per cent compared with 39 per cent in Reiter's disease; destructive changes were also seen more commonly in the metacarpo-phalangeal joint in rheumatoid arthritis, but the most striking difference was in narrowing of the metacarpo-phalangeal joints. It was relatively rare in Reiter's disease (11 per cent) but was observed in 81 per cent of the cases of rheumatoid arthritis. In ankylosing spondylitis the hand lesions are rare but they seem to follow the same pattern as in Reiter's disease.

\section{DISCUSSION}

We have found no absolute means of differentiating the conditions radiologically in all cases; indeed some patients have had repeated attacks of Reiter's disease without showing radiological change. But we believe that in many patients help can be given by radiology and we suggest that the following points might be helpful.

Reiter's disease-The changes are predominantly in the feet and sacro-iliac joints. In the feet, in addition to destructive joint changes and consequent deformity, exuberant (as opposed to simple linear) periosteal new bone formation tends to occur at the calcaneum, and it may also occur to a lesser extent at the wrist. Asymmetrical bone and joint involvement is a characteristic but not invariable feature whereas generalised osteoporosis is not. Hand changes are mild, even when the wrist is severely involved. We consider that the presence of large rough spurs with fluffy periosteal new bone on the plantar surface of the calcaneum is characteristic of Reiter's disease.

Rheumatoid arthritis-The generally accepted appearance in rheumatoid arthritis-that is, a tendency to be symmetrical, to be associated with osteoporosis and to affect hands and feet equally-is confirmed. The sacro-iliac joints, when affected, show only mild changes.

Ankylosing spondylitis-Some patients with Reiter's disease have been seen to develop an 
"ankylosing spondylitis," and some patients with ankylosing spondylitis cannot be differentiated radiologically. In most patients with ankylosing spondylitis the great predominance and early appearance of sacro-iliac changes and the mild involvement of the feet is in contrast to the severe affection of the feet and late development of sacro-iliitis in Reiter's disease.

\section{CONCLUSIONS}

1. Sacro-iliitis is a common radiological finding in Reiter's disease: it develops slowly and is present in over half the patients with a history of five years or more. We are not so far able to distinguish any qualitative difference between the three diseases with early changes, without considering the relationship of the sacro-iliitis to spondylitic changes in the spine and to the duration of disease, but advanced changes were not seen in rheumatoid arthritis.

2. Florid periostitis is very suggestive of Reiter's disease, and when it occurs on the plantar aspect of the calcaneum it is probably pathognomonic. Simple spurring and erosion of this bone as defined here was present in all three groups.

3. Certain differences appear in the radiological appearances of the hands and feet, but a radiological distinction may be extremely difficult on the basis of these alone, apart from the periostitis mentioned above.

\section{SUMMARY}

The radiological appearances in twenty-five patients with Reiter's disease have been compared with those in eighty-one with rheumatoid arthritis and thirty-eight with ankylosing spondylitis. The similarities and differences have been analysed. Changes of periosteal new bone in the calcaneum appear to be the only significant differentiating factor, although minor differences in incidence and distribution occur elsewhere. Sacro-iliitis is a common radiological feature of long-standing Reiter's disease.

We would like to record our thanks to Miss P. H. Burgess, A.R.P.S., for her help in preparing the radiographic reproductions.

\section{REFERENCES}

Buchan, J. F. (1955): Reiter's Disease: A Review of the Present Position. Proceedings of the Royal Society of Medicine (Section of Physical Medicine), 48, 432.

Bywaters, E. G. L. (1954): Heel Lesions of Rheumatoid Arthritis. Annals of the Rheumatic Diseases, $13,42$. CORNer, B. D. (1950): Reiter's Syndrome in Childhood. Archives of Disease in Childhood, 25, 398.

FORD, D. K. (1953): Natural History of Arthritis Following Venereal Urethritis. Annals of the Rheumatic Diseases, 12, 177.

Guck, J. K., and Wolf, J. (1952): Monarticular and Destructive Arthropathy in Reiter's Syndrome. American Journal of the Medical Sciences, 224, 653.

HARKNess, A. H. (1950): Non-Gonococcal Urethritis. Edinburgh: E. \& S. Livingstone Ltd.

Hollander, J. L., Fogarty, C. W., Jun., Abrams, N. R., and Kydd, D. M. (1945): Arthritis Resembling

Reiter's Syndrome. Journal of the American Medical Association, 129, 593.

Kellgren, J. H., and Lawrence, J. S. (1957): Radiological Assessment of Rheumatoid Arthritis. Annals of the Rheumatic Diseases, 16, 485.

KING, A. J. (1957): Arthritis and Venereal Urethritis. Abstracts of Reports and Papers 11th International Congress of Dermatology, Stockholm, July 31-August 6, 1957. Excerpta Medica, Section 13, 11, No. 8, p. 125.

MARChe, J. (1950): L'atteinte des articulations sacro-iliaques dans le syndrome "dit" de Reiter. Revue du Rhumatisme, 17, 449.

Mason, R. M., Murray, R. S., Oates, J. K., and Young, A. C. (1958): Prostatitis and Ankylosing Spondylitis. British Medical Journal, i, 748.

Murray, R. S., Oates, J. K., and Young, A. C. (1958): Radiological Changes in Reiter's Syndrome and Arthritis Associated with Urethritis. Journal of the Faculty of Radiologists, 9, 37.

OAtes, J. K. (1957): The Role of the Prostate in Non-specific Urethritis. Abstracts of Reports and Papers 11 th International Congress of Dermatology, Stockholm, July 31-August 6, 1957. Excerpta Medica, Section 13, 11, No. 8, p. 126.

Paronen, I. (1948): Reiter’s Disease. Acta Medica Scandinavica, Supplementum 212.

SharP, J. (1957): Differential Diagnosis of Ankylosing Spondylitis. British Medical Journal, i, 975.

Thомpson, M. (1957): Discussion on the Clinical and Radiological Aspects of Sacro-iliac Disease. Proceedings of the Royal Society of Medicine (Section of Physical Medicine), 50, 847.

Twiss, J. R., and Douglas, A. H. R. (1946): Reiter's Disease: a Report of Two Cases. Annals of Internal Medicine, 24, 1,043. 